\title{
Fact or Fiction: Qualitative Research Results in Information Systems
}

\author{
Kay Fielden \\ UNITEC Institute of Technology, Auckland, New Zealand
}

kfielden@unitec.ac.nz

\begin{abstract}
In this discussion paper multiple points of view, and effects and sources of bias in qualitative research results in organizational information systems are explored. A generic qualitative research process is traced starting from the ways in which researchers obtain permission to gather data in organizations. Multiple points of view in the research process, all of which may introduce bias into research results, are considered next. These include researcher/s, research institution, funding body, client organization, and individual participants. Finally bias effects from these multiple points of view are considered at analysis, interpretation and reporting of research results for organizational information systems. The position taken in this paper is that there is inevitable bias in qualitative research that may have many effects. The appropriateness of a 'scientific' approach to bias in qualitative research in organizational information systems is also considered.
\end{abstract}

Keywords : qualitative research, bias, information systems

\section{Introduction}

Janesick (2000) suggests that bias in qualitative research is inevitable. (Glasser, 1992; Strauss \& Corbin, 1998) however, state that bias is not only inevitable but also desirable. Starting from the premise that in qualitative research, the researcher is the primary instrument of research, it appears inevitable that the data that he/she gathers, regardless of research method employed, will be biased.

In this discussion paper, multiple points of view, and the effects and sources of bias in qualitative research results in organizational information systems are explored. A generic qualitative research process is traced starting from the ways in which researchers obtain permission to gather data in organizations.

Multiple points of view in the research process, all of which may introduce bias into research results, are considered next. These include researcher/s, research institution, funding body, client organization, and individual participants. Finally bias effects from these multiple points of view are considered at analysis, interpretation and reporting of research results for organizational information systems. The position taken in this paper is that the inevitable bias in qualitative research may have many effects. The appropriateness of a 'scientific' approach to bias in qualitative research in organizational information systems is also considered (Lincoln \& Guba, 2000).

Material published as part of these proceedings, either on-line or in print, is copyrighted by Informing Science. Permission to make digital or paper copy of part or all of these works for personal or classroom use is granted without fee provided that the copies are not made or distributed for profit or commercial advantage AND that copies 1) bear this notice in full and 2) give the full citation on the first page. It is permissible to abstract these works so long as credit is given. To copy in all other cases or to republish or to post on a server or to redistribute to lists requires specific permission from the publisher at Publisher@InformingScience.org

\section{Qualitative Research in Information Systems}

Qualitative research inevitably involves the researcher's own po int of view, which in turn contains an element of researcher 'bias'. Regarding this as strength, (rather than as weakness) adds to the richness of knowledge about complex situations and problems that have been hard to solve. 


\section{Fact or Fiction: Qualitative Research Results}

Qualitative research is necessarily biased - the researcher participates in the research and takes a stand and (whether aware or unaware) colours the results and interpretations of results with own mindset (Janesick, 2000; Nand hakumar \& Jones, 1997).

Qualitative research is bounded in the context in which the research takes place. Any results or conclusions are 'true' only in that particular setting. Results therefore cannot to be generalised. An appropriate way to consider the results of qualitative research is to view results from any one particular research situation as adding to the pool of knowledge about similar problems upon which meta-analysis can then be performed. Adding to the total knowledge pool, rather than generalizing about single 'truths', to produce trends, clusters, peaks, troughs and isolated results is a more appropriate way to interpret qualitative research results.

Qualitative research in information systems has the ability to go beyond the rational domain. Scientific methods, statistics, scientific design, quasi-design, surveys, questionnaires, interviews and observations belong to the rational research domain. Qualitative research has at its fingertips many more ways of gathering data - silence, creativity, movement, direct knowing, intuitio n, flow, . . Other 'truths' may be valid outside of the world of science and statistics that may be considered, analysed and interpreted to reach quite different conclusions (Lincoln \& Guba, 2000). As such research results are unknown to the quantitative research arena, they may be considered erroneous, invalid or biased.

There is a gathering momentum for qualitative research in information systems (Lau, 1998; Lee, 2001; Myers, 1997; Trauth, 2001). It is time to explore perceived problems for research in this field especially in light of the large number of failed organizational information systems reported.

Kincheloe \& McLaren (2000) state that 'claims to truth are always discursively situated and implicated in relation to power' and that 'truth involves regulatory rules that must be met for some statements to be more meaningful than others'. Because the qualitative researcher is the primary instrument of research, interpreting such 'claims to truth' must be filtered through the researcher's conceptual models, beliefs and prejudices. It is a wise and experienced qualitative researcher who has reached the position of being fully aware.

Olesen (2000) suggests that when the researcher becomes aware of the 'cultural self' there is an additional set of resources upon which to draw in interpreting qualitative research results. (Krieger, 1991) states that realization of the self is fundamental to qualitative research. She also suggests that this realization of self is evoked through reflexivity and the related issues of subjectivity in the research process.

Becoming a 'wise' qualitative researcher requires training, both academic and personal to raise the level of awareness of 'self in the process' and inherent self-bias. The author has developed self-awareness through, academically through doctoral studies in social ecology where the basic philosophical approach was to perform qualitative research in organizations. Multip le points of view were embedded within a soft systems thinking framework to conceptualize the research problem being considered. At the same time, through meditation practices, the author has deve loped a level of self-awareness, both within the self and in relation to others. The ability to still the mind together with intellectual development has enabled the author to become a 'wiser' qualitative researcher aware of self-bias throughout the research process.

\section{Research Dilemmas in Qualitative Research}

\section{The Researcher}

As the qualitative researcher in information systems is the primary instrument for the research process (Janesick, 2000), it is inevitable that the researcher will bring to the research process an individual mindset, biases, skills and knowledge. 


\section{The Research Process}

The qualitative research process includes such generic tasks as: asking the right questions, gathering the right data, measuring the data collected, analyzing the measurements, interpreting the analysis to reach conclusions, controlling the research process by clear boundaries, informed consent and ethical approval and employing an appropriate research methodology.

The dominant paradigm within information systems is one in which validity and truth is considered to be universal and singular. In the particular world of qualitative research, validity may take on multiple meanings. Bias in qualitative research can and does affect all stages of the process - from inception to published results and implementation of change. At each stage of the research process, the many stakeholders involved have opportunities to introduce bias that will affect research results.

\section{Bias In Qualitative Research In Information Systems}

Microsoft Word Thesaurus suggests that bias could be prejudice, partiality, unfairness, preconceived notions, foregone conclusions, favoritism, predisposition, or preconception. In the world of information systems, results bias is generally taken to mean subjective interpretation, not objective, that may be influenced by the researcher, participants, funding agencies, research institutions, client organizations, or individual participants in the research process. Whilst bias of any kind is rigorously guarded against in scientific research, it is inevitable in qualitative research. Unfortunately, for the qualitative researcher who elects to use a quantitative research paradigm, scientific and objective results are often viewed with disdain. This paper will consider whether the concept of bias is valid in qualitative research.

Bias can be present in Information Systems research through the researcher, the way in which data is collected, the research methodology selected, the way in which sampling is done, analysis techniques employed, and the way in which the analyzed results are interpreted. Bias can also be present in the discipline. It could be said that because research in information systems is dominated by quantitative methods that a bias against qualitative research exists.

Bias may exist in the body of knowledge in which a particular research project is situated. For instance, the client organization may dictate the form of the research and the expected outcomes required. Research results may be biased by the acceptance or rejection of change that published results indicate. Finally, bias may exist because any or all of those involved in the research process are not aware of other ways of knowing (Belenky, Clinchy, Goldberger, \& Tarule, 1986). Results may be rejected because the researc her utilized 'other ways of knowing' throughout the research process. If any stak eholder in the research process is unaware of their own bias, this in turn affects the results.

\section{The Bounds Of This Discussion Paper}

This discussion is set within the following parameters:

- Only qualitative research carried out in organizations in information systems;

- The discussion centers on generic rather than specific qualitative research methods;

- The qualitative research methods considered are only those involving interactio ns between the researcher and members of organizations. This could be considered to be practical rather than theoretical qualitative research. Whilst mental models used to make sense of qualitative research results will be considered, the research domain is limited to human interactions in organizations in which information systems exist;

- The inevitability of bias in qualitative research results;

- Multiple aspects of bias in such qualitative research;

- The notion of multiple realities and multiple points of view rather than just one point of view on what qualitative research results mean; 


\section{Fact or Fiction: Qualitative Research Results}

- The relationship between the emergent nature of qualitative research and bias;

- The ability of qualitative researchers to engage in dynamic, emergent research; and

- Finally, missed information in emergent research and the effect this has on bias in qualitative research.

\section{Before Qualitative Research Starts}

Before any research in organizations can take place, informed consent must be obtained. The reality of this process for those within organizations and the participants in the research process, may take a number of different forms.

Possible scenarios are:

The qualitative researcher obtains consent for the research from all those within the organization - from the chief executive to the lowest worker. Everybody in the organization has discussed the research to be carried out, knows the steps in the research process, understand what each participant's contribution will be and what the expected research outcomes are. In this scenario, the qualitative researcher is in the best possible situation to collect data. The research process within the organization is open, democratic, and fully participatory.

In the second scenario, the qualitative researcher obtains consent from the chief executive to carry out the research within the organization. The chief executive sends out a statement to all staff requesting that they cooperate with the researcher for the benefit of the organization. In this scenario all staff know that the research is to take place. However, participants do not know the whole research process, individual or collective commitment required, and staff were not part of the initial decision-making process to allow the research to take place. In this scenario, the research process is not democratic or fully participatory. Whilst information has been disseminated about the research, individuals within the organization have not been empowered by being part of the decision- making process. In such a research process there is more likelihood that points of tension will exist when the qualitative researcher approaches employees at data collection time. There is the likelihood that data gathered in this scenario will be influenced by a consent process that did not empower emp loyees.

The third scenario is one in which consent is granted by chief executive for the research process and no communication with staff is made. The qualitative researcher arrives to gather data from participants who know nothing about the research process. The likelihood of skewed or biased data gathered from these employees is high. The source of bias in this scenario lies within a corporate climate in which e mployees have not been informed. This in turn is highly likely to engender negative feelings about participation in the research process.

\section{When the Data is Being Gathered}

Stakeholders involved when data is being gathered include:

Qualitative researcher/s. Regardless of the level of participation in the decision-making process within the organization about this particular research project, the researcher/s instigate and drive data gathering. The researcher/s control the data gathering mechanism employed and timing. They also decide on the level of involvement (Figure 1).

Individual participants. Data is gathered directly from individual participants within client organizations. The way in which each individual participant responds may be affected by organizational culture -- which includes the way consent was granted, trust within the organiza tion, and perceived power imbalances within the research process. Individual participants are more likely to give guarded responses if the que stions being asked are perceived to be a threat within the organizational research setting. 


Distance
Analysis of published data
Textual analysis
Survey
Interview (structured $>$ semi $>$ unstructured)
Passive observation (and lab experiment)
Participant observation
Action research
Consultancy

Figure 1: Distance and engagement between researcher and subject with different data gathering methods (Nandhakumar \& Jones, 1997)

Funding agencies and research institutions. These are not usually directly involved in gathering research data.

\section{Analyzing Qualitative Research Results}

Qualitative researcher/s are the primary stakeholder when qualitative research data is analyzed. Bias may be introduced through:

1. Researcher mindset. One of the most difficult attributes to acquire and use effectively in qualitative research in organizational information systems is the ability to encompass multiple mindsets. The inability to accept and understand multiple stakeholder points of views may bias research results.

2. Discarding emergent data. Qualitative research is characterized by emergence. Unexpected results can and do happen in qualitative research. It is very easy and tempting to discard emergent data especially when it is not aligned with the original research question. The qualitative researcher requires the ability to cope with uncertainty and chaotic situations in such research situations. Discarding emergent data and /or results are another source of research bias.

3. Skill level in handling multiple datasets. Most qualitative researchers in organizational information systems gather data in multiple ways. For instance a case study may involve observation, data mining, in-depth interviews and a focus group. Each data gathering method requires different researcher skills. Differing levels of skills in the methods employed within the research method chosen may introduce bias.

\section{Making Sense of Qualitative Research Results}

Whilst qualitative researchers are informed by and consult with other stakeholders in the research process it is when qualitative research results are interpreted that the qualitative researcher bias is most likely to be present. Interpreting qualitative results is a complex activity requiring conceptual models or frameworks (Figure 2), a quiet mind to allow intuitive interpretations to emerge, and a high level of selfawareness as results are being interpreted. Intellectual ability alone does not provide an interpretative mindset that is capable of undertaking this difficult task. Without developing a certain degree of wisdom the qualitative researcher is likely to remain unaware of any personal bias introduced. It is this awareness of personal bias that is important - not whether bias is present or not. 


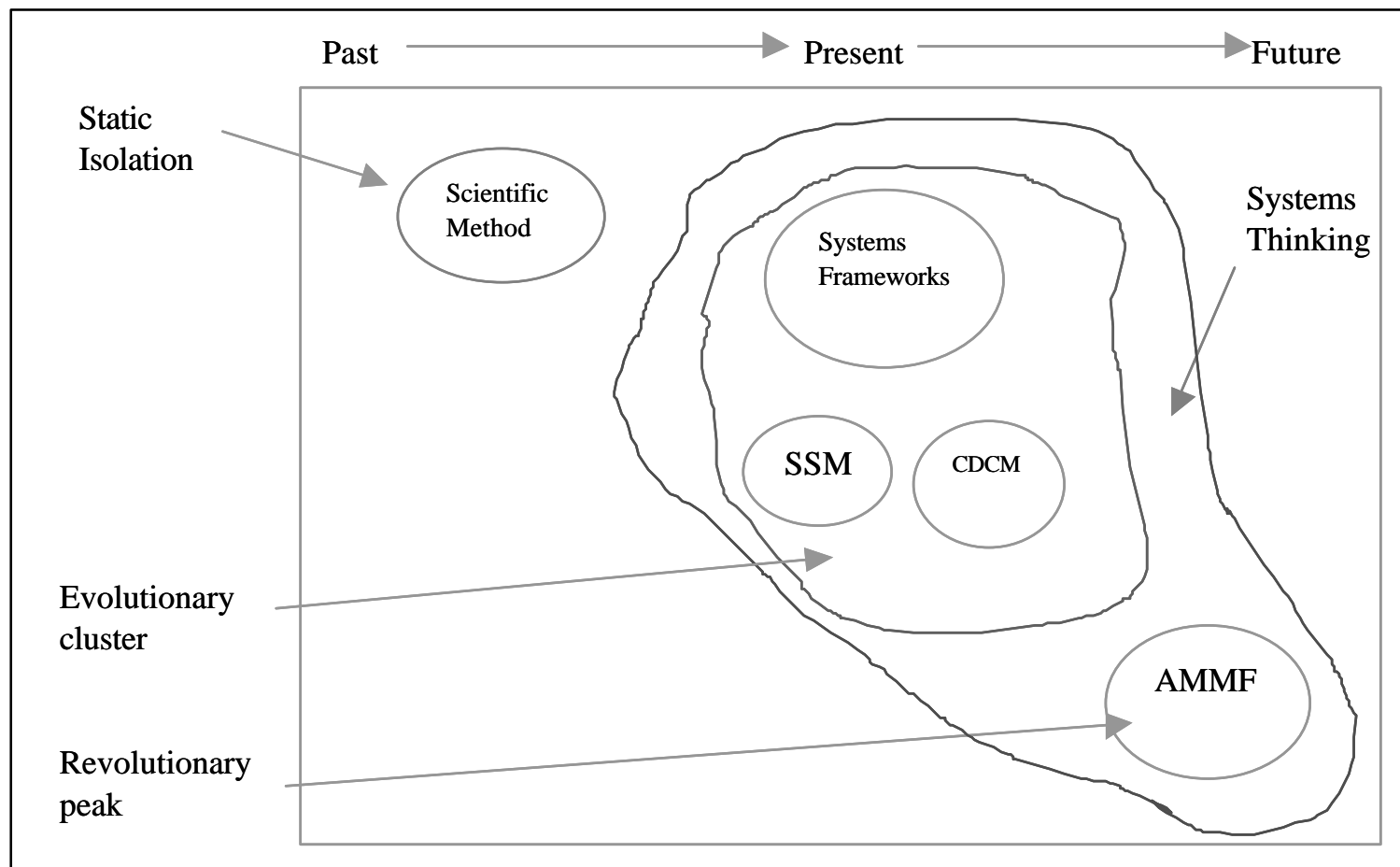

Figure 2: Sense-making Interpretive Framework

Without the ability to 'tune into' intuitive processes, the qualitative researcher may not be aware of emergent interpretations. The degree of awareness has inevitable researcher bias because such intuitive processes are embedded deeply within the researcher.

Making sense of qualitative research results in organizational information systems is an activity driven by the researcher/s. It is through the interpretive eyes of the researcher - with differing levels of input from other stakeholders - that sense is made of research results.

The intellectual and conceptual interpretive framework adopted sits within a rich landscape of interpretive mindsets (Figure 2). Interpretations lie within a past/present/future spectrum as well as an isolationist, evolutionary or revolutionary dimension (Fielden, 2002). The mindset adopted in forming the particular intellectual interpretive framework for the research results being considered is yet another avenue in which bias may occur.

In Figure 2 below SSM (Soft Systems Methodology) (Checkland \& Scholes, 1990) evolved from within the general systems theory movement in response to solving 'soft' systems within organizations. The theoretical development of CDCM (Context Dependent Cluster Model) (Fielden \& London, 2001) extended the theoretical development of Checkland, situating the theoretical domain within complexity theory as well as SSM and applying this systems framework at a micro rather than a macro level. Such evolutionary development belongs in a mental mindset cluster (figure 2).

Whilst Agile Mental Model Formation (AMMF) (Fielden, 2002) lie within the general arena of theoretical conceptual modeling, it does not sit within the evolutionary cluster containing general systems frameworks, SSM and CDCM. The theoretical foundations of AMMF lie within the domain of systems thinking, and are informed by evolutionary mental model formation. AMMF as a new theory allows alternate theories to enter from inter- and multi-disciplinary multiple levels of thought formation.

AMMF is informed by vulnerability in systems particularly with regard to the ability to cope with rapid change (Boulding, 1989), Lewin's (1958) 'free ze-frame' theory, the ability to accept other than rational solutions (Ornstein, 1991), the ability to engage with multiple truths (Maturana \& Varela, 1998), engag- 
ing in mental model formation collaboratively as well as privately (Wheatley, 2000), and mental trans ition states in times of change (Bridges, 1991).

Traditionally sense-making in information systems research occurs within the objective mindset required in science. It can be seen from Figure 2 that such mental model formation is more likely to be located within an isolationist mindset more influenced by the past than the future. Such objective mindsets are also more likely to be fixed and disallow the multiple truths and rapid movement required to deal with dynamic research results. The research arena being considered by this paper is one in which dynamic and flexible mindsets located at least within the systems thinking domain as shown in Figure 2 are required. Bias is introd uced into the sense-making process when there is reduced ability to move within the rich mental model landscape of systems thinking.

\section{Presentation of Results}

All stakeholders are involved and may introduce elements of bias when results are presented. Results may be presented via publications to the research community including research institutions, funding bodies and wider community of information systems researchers. Reviewing panels for academic publications and conferences are yet another arena in which bias may occur especially when the research lies outside the dominant paradigm for the discipline. Results may be presented to client organizations and participants via client presentations and reports. Expectations conveyed during the whole of the research process may bias final results.

\section{Implications}

The major implications arising form this discussion paper include the following:

- That bias is inevitable and may arise from multiple sources and at any stage in qualitative research in organizational information systems.

- That bias may not be an appropriate construct to consider in qualitative research in organizational information systems.

- That qualitative researchers in organizational information systems need to be multiskilled and mentally agile to cope with the complexities that arise in considering the multiple ways in which bias may occur.

- That the qualitative researcher in organizational information systems may need to de velop skills outside of the dominant research paradigm.

- That the qualitative researcher in organizational information systems needs to adopt theoretical principles that align with the complex nature of research in organizational information systems.

\section{Conclusion}

In this paper, the rich domain of bias in qualitative research in organizational information systems has been considered. Bias may be introduced at any stage of the qualitative research process from multiple stakeholders. It is worth considering whether or not bias is an appropriate construct for qualitative research in organizational information systems. An appropriate way to consider the results of qualitative research is to view results from any one particular research situation as adding to the pool of knowledge about similar problems upon which meta-analysis can then be performed. Adding to the total knowledge pool, rather than generalizing about single 'truths', to produce trends, clusters, peaks, troughs and isolated results, is a more appropriate way to interpret qualitative research results.

Fact or fiction depends on a particular point of view in qualitative research. In information systems, that has long been dominated by quantitative research, qualitative methods with the inevitable multiple sources of bias may indeed appear to be fiction. 


\section{References}

Belenky, M. F., Clinchy, M. B., Goldberger, N. R., \& Tarule, J. M. (1986). Women's Ways of Knowing. New York: Basic Books, Inc.

Boulding, K. E. (1989). Towards a Theory of Vulnerability. Journal of Applied Systems Analysis, 16, 1-17.

Bridges, W. (1991). Managing Transitions: Making the Most of Change. USA: Addison-Wesley Pub Co Inc.

Checkland, P., \& Scholes, J. (1990). Soft Systems Methodology in Action. Chichester: Wiley.

Fielden, K.(2002). Agile Mental Model Formation: A Systems Framework for Discontinuous Change. presented at ANZSYS2002 conference. Mooloolaba, Australia.

Fielden, K. \& London, K. (2001). Engaging Existing Staff as New Postgraduate Students in the Research Process. in Proc ANZSYS2001 conference, Perth pp312-321.

Glasser, B. G. (1992). Basics of grounded theory analysis: Emergence versus forcing. Mill Valley: Sociology Press.

Janesick, V. (2000). The Choreography of Qualitative Research Design: Minuets, Improvisations, and Crystallization. In N. K. Denzin \& Y. S. Lincoln (Eds.), The Handbook of Qualitative Research (pp. 379-400). Thousand Oaks, California, Sage Pub.

Kincheloe, J. L., \& McLaren, P. (2000). Rethinking Critical Theory and Qualitative Research. In N. K. Denzin \& Y. S. Lincoln (Eds.), The Handbook of Qualitative Research (pp.279-314). Thousand Oaks, California, Sage Pub.

Krieger, S. (1991). Social Science and the Self: Personal Essays on an Art Form. New Brunswick, Rutgers University Press.

Lau, F. (1998). Towards a Framework for Action Research in Information Systems Studies. .

Lee, A. S. (2001). Challenges to Qualitative Researchers in Information Systems. In E. M. Trauth (Ed.), Qualitative Research in IS: Issues and Trends (pp. 240-270). USA: Idea Group Publishing.

Lincoln, Y. S., \& Guba, E. G. (2000). Paradigmatic Controversies, Contradictions, and Emerging Confluences. In N. K. Denzin \& Y. S. Lincoln (Eds.), The Handbook of Qualitative Research (pp. 163 -188). Thousand Oaks, California, Sage Pub.

Maturana, H., \& Varela, F. (1998). The Tree of Knowledge: the biological roots of human understanding: Shambala.

Myers, M. D. (1997). Qualitative Research in Information Systems. MISQ, 21(2), 241-243.

Nandhakumar, J., \& Jones, M. (1997). Distance and engagement in IS research. Information Systems Journal, 7 (2), 109-131.

Olesen, V. L (2000). Feminisms and Qualitative Research At and Into the Millenium. In N. K. Denzin \& Y. S. Lincoln (Eds.), The Handbook of Qualitative Research (pp. 215-256). Thousand Oaks, California: Sage Pub.

Ornstein, R. (1991). The Evolution of Consciousness: the Origin of the Way We Think. New York: Simon \& Schuster Inc.

Strauss, A. L., \& Corbin, J. (1998). Basics of Qualitative Research: Techniques and procedures for developing grounded theory. (2nd ed.). Thousand Oaks: Sage.

Trauth, E. M. (Ed.). (2001). Qualitative Research in IS: Issues and Trends. USA: Idea Group Publishing.

Wheatley, M. (2000). Innovation Means Relying on Everyone's Creativity. Four Directions Library. USA.

\section{Biography}

Kay Fielden holds a $\mathrm{PhD}$ and a postgraduate Diploma in Social Ecology from the University of Western Sydney, Australia, an MSc in Computer Science from the University of New South Wales and a $\mathrm{BSc}(\mathrm{Hons})$ from Canterbury University, New Zealand. Currently she is research coordinator for the School of Computing and Information Technology at UNITEC Institute of Technology, Auckland, New Zealand and is responsible for both staff and postgraduate student research. 